\title{
A Transit Access Analysis of TANF Recipients in Portland, Oregon
}

Thomas W. Sanchez, Portland State University

\begin{abstract}
Little evidence exists regarding the relationship between transit service availability and the ability of welfare recipients to find stable employment. While policymakers continue to assert that increased public transit mobility can positively affect employment status, there is little empirical evidence to support this theory. It is generally assumed that public transit can effectively link unemployed, carless persons with appropriate job locations. From these assumptions stems the common belief that if adequate transit were available, the likelihood of being employed would increase. Hence, the call for more transit services to assist moving welfare recipients to gainful employment. Current available evidence is anecdotal, while general patterns of transit access and labor participation remain relatively unexplored.

This analysis examines whether transit access service is less available to Temporary Assistance for Needy Families (TANF) recipients in the City of Portland, Oregon. It uses disaggregate TANF recipient location data from the State of Oregon Department of Adult and Family Services (AFS); transit route/stop data from Tri-Met; block-group census data; and disaggregate employment location data within Geographic Information Systems (GIS). GIS capabilities are essential in performing
\end{abstract}


network accessibility analyses and for analyzing spatial patterns of TANF recipient and employment locations. The results of this analysis provide an assessment of the availability and quality of transit service for TANF recipients.

\section{Introduction}

The Personal Responsibility and Work Opportunity Reconciliation Act of 1996 is a renewed effort to move persons from welfare rolls to stable employment. This legislation attempts to provide states with more flexibility in assisting low-income households and also to provide incentives for states to reduce welfare caseloads. The revised system is administered through the TANF program (formerly Aid to Families with Dependent Children), which institutes increasingly severe time restrictions and qualifying criteria (Danziger et al. 1999).

Recognizing the fact that most of the households within the TANF program have limited transportation mobility, $\$ 750$ million was allocated over five years for job access and reverse commute programs (Surface Transportation Policy Project 1998). Because low-income households have especially low rates of automobile ownership, with many having no access to an automobile, they depend on public transit, which then affects the locations and types of employment that are available to them (Murakami and Young 1997; Coulton, Leete, and Bania 1997). Some argue that public transit is not a viable alternative to the personal automobile due to the extent of geographic imbalance between housing and jobs (Wachs and Taylor 1998; Ong and Blumenberg 1998). The result is a significant challenge routinely faced by transit operators: to provide effective service despite increasing automobile dependency as well as dispersed and transit-inaccessible land-use patterns. The spatial mismatch between the residential location of low-income, urban households and the location of new low-skill jobs has received considerable attention in the academic literature (Ihlanfeldt and Sjoquist 1998).

Transit agencies have faced reduced ridership and revenue amid simultaneous demands for new service to dispersed employment in the suburbs that is inherently more costly to provide. Transit service also operates in a political 
environment where the costs of marginal increases in service levels may encounter opposition due to competing objectives from other public agencies (Wachs 1995). If urban service is less utilized than it once was, but is still desired by remaining transit customers, it is difficult to sustain political arguments to provide new services where the current demand is smaller or latent and the automobile is the focus of land-use development activities.

While transit routes are designed, in part, to serve worktrips in urban areas, little evidence exists regarding the relationship between transit service provision and labor participation rates. Policy-makers continue to assert that employment status is a function of transportation mobility, despite limited empirical evidence to support this theory. It is generally assumed that public transit can effectively link unemployed, carless persons with appropriate job locations. The common belief, based on these assumptions, is that adequate public transit increases a worker's likelihood of being or staying employed (U.S. Department of Transportation 1998). Hence the call for more transit services to assist moving welfare recipients to stable employment. Available evidence to date is anecdotal; general patterns of transit access and labor participation are now becoming the focus of many analyses-especially with the use of GIS.

GIS is being used increasingly to better understand the spatial dimension of where TANF recipients live and the location of appropriate job opportunities. A range of research has operationalized employment and transit accessibility measures for low-wage workers (Community Transportation Association of America 1998; Lacombe and Lyons 1998). In most cases, the use of GIS is limited to mapping concentrations of TANF recipients and job opportunities rather than being used for spatial analyses to generate solutions to associated transportation planning problems. Some have utilized more advanced methodologies that empirically examine the spatial relationship between jobs, transit, and employment outcomes (Shen 1998; Thompson 1997; Sanchez 1999). The use of GIS will likely increase for these purposes as there is further recognition of the benefits of geographical analysis. 


\section{Hypotheses}

This analysis examines three hypotheses for TANF recipients in the City of Portland, Oregon. These hypotheses address whether TANF recipients experience lower levels of transit and employment access compared to the overall population of workers. The three hypotheses are:

1. TANF recipients have less physical access to transit stops compared to other transit commuters.

2. TANF recipients live in areas with less frequent transit service compared to other transit commuters.

3. TANF recipients have less transit access to entry-level employment locations compared to other transit commuters.

The first hypothesis concerns the level of transit access available to TANF recipients. Transit access is typically considered adequate if persons live within a 0.25 -mile walking distance to the nearest transit stop (Urban Mass Transportation Administration 1979). The implicit assumption is that their final destination is also within walking distance to a transit stop. Beyond 0.25 mile, the time cost and inconvenience usually inhibit transit usage. The mean walking distance to the nearest transit stop for TANF recipients is compared to the mean distance from block-group centroids. The centroid represents the "average" location of residents within each block group. For comparison purposes, each centroid is weighted by the number of workers reporting that they use transit to get to work (from the 1990 census). If the average walking distance to the nearest transit stop for TANF recipients is greater than that of other transit commuters, it would indicate that transit is less accessible to TANF recipients.

The second hypothesis considers the quality of transit service. Along with physical proximity to stops, service frequency also has a significant affect on ridership (Black 1995). Mobility levels increase when riders are not limited by infrequent or unreliable transit availability. To test the second hypothesis, the mean peak scheduled service frequency (7 A.M. to 9 A.M..) at the nearest transit stop for all TANF recipients is compared to the mean service frequency for frequent transit commuters (by block group). If the service frequency for TANF recipients is significantly less than that of transit users, the utility of 
transit for recipients will be lower than for locations with more frequent service. The measures of service quality and proximity provide useful indicators of whether TANF recipients are at a disadvantage in terms of mobility given that their vehicle ownership rates are very low.

The third hypothesis focuses on issues related to the spatial mismatch hypothesis and job accessibility that are central to welfare-to-work initiatives. One solution to the spatial mismatch of worker and job locations is to increase transportation mobility levels, especially relative to entry-level employment locations. The underlying assumption is that shifts in new employment locations have produced a geographic separation between residences and jobs that has contributed to higher levels of employment instability. For this reason, if job accessibility increases through improved public transit services, then labor participation levels should increase. The measures of job accessibility for TANF recipients include only entry-level positions because recipients have generally low levels of educational attainment and job skill levels (Immergluck 1998). The mean number of retail and service employment locations (considered to be entry level or low skill) that can be reached using transit is used to test whether TANF recipients have lower levels of transit access to these jobs compared to other employed persons that rely on transit.

\section{Methodology}

The AFS provided an address database for TANF recipients in the Portland metropolitan area. A total of 5,186 out of 5,286 records were geocoded for the City of Portland. Of the 100 unmatched records, 92 could not be matched to street addresses because the recipient was homeless or listed a post office box for their home address. Along with street addresses, AFS provided demographic characteristics about each recipient and their current status. In summary, approximately half $(56.6 \%)$ of Portland TANF recipients are white and predominantly female (79.6\%). On average, recipients are 32 years old with less than 11 years of education. More than half of TANF recipients have received assistance for 12 months or less while approximately 20 percent have received assistance for more than four years.

Along with the disaggregate TANF recipient location data, the analysis 
uses transit route and stop data from Tri-Met; 1990 block-group census data; and disaggregate employment location data within a GIS. GIS capabilities are essential in performing network accessibility analyses and for analyzing spatial patterns of TANF recipient and employment locations. For each TANF recipient location and block-group centroid the distance along the street network to the nearest transit stop is used as an estimate of walking distance. This assumes that pedestrian facilities are available along each street segment. Similarly, the average peak-hour service frequency at the nearest stop (in terms of minimum walking distance) is assigned to each TANF and block-group centroid location. Both the walking distance and service frequency measures assume that persons use the nearest transit stop location-which may be true in most, but not all cases.

For service and retail job locations, an employment accessibility index was calculated for each TANF recipient and block group. Recipient locations and block-group centroids were used as trip origins with the locations of service and retail jobs as destinations. An average total travel time of 60 minutes with 10-minute penalties for transfers was used for job accessibility calculations. Significantly lower levels of job access for TANF recipients may suggest that spatial mismatches are a factor contributing to low rates of labor participation. The accessibility calculations are based on the following equation and estimated using a GIS:

where:

$$
P_{i}=\sum_{j=1}^{n} W_{j} d_{i f}^{-\beta}
$$

$P_{i}$ is the employment accessibility of TANF recipient or block group $i$.

$W_{j}$ is the number of jobs within walking distance of each transit stop j.

$d_{i j}$ is the travel time between $\mathrm{i}$ and $\mathrm{j}$.

$\beta$ is the exponent for distance decay ( 2 used for this analysis).

$n$ is the number of transit stops in the study area.

\section{Results}

Statistical tests were used to determine if a significant difference exists 
between mean values of transit access and employment access for TANF recipients compared to other transit commuters. Mean tests were also applied to the employed population for comparison purposes. The tests were conducted by comparing the mean values for TANF recipients to the mean values for block groups (weighted by the number of workers using transit for worktrips and also weighted by the total number of employed persons for each block group). The statistical results suggest that on average, TANF recipients live slightly closer to transit services than do other frequent transit commuters (Table 1). The average distance to the nearest stop for TANF recipients is also less than that of the overall employed population. This indicates that TANF recipients do not suffer disproportionately from poor physical access to transit routes.

\begin{tabular}{|lcccc|}
\hline \multicolumn{5}{|c|}{ Table 1 } \\
& \multicolumn{5}{c|}{$\begin{array}{l}\text { Standard } \\
\text { Deviation } \\
\end{array}$} & \multicolumn{5}{c}{ Mean } & $(S D)$ & $N$ & t-test $^{\mathrm{a}}$ \\
\cline { 2 - 5 } & & & & \\
TANF & 0.185 & 0.124 & 5,185 & - \\
Transit commuters & 0.196 & 0.128 & 20,616 & $<.005$ \\
All workers & 0.249 & 0.203 & 236,634 & $<.005$ \\
\hline
\end{tabular}

a. Two-tail significance, $t$-test for equality of means (compared to TANF observations).

While TANF recipients in Portland appear to live in areas with nearby transit services, the frequency of scheduled service near them tends to be slightly less than that of frequent transit commuters (Table 2). The average difference in service frequency is approximately 0.5 minutes, while the overall employed population averages approximately 2 minutes less frequent service than do TANF recipients. While transit service frequency is an important indicator of service quality, the 0.5 -minute average difference with transit commuters does not represent a distinct disadvantage for TANF recipients.

Walking distance to the nearest transit stop and service frequency at the nearest stop serve as transit system access measures. Transit access will only 
Table 2

Peak Service Frequency at Nearest Transit Stops (mins)

\begin{tabular}{llll}
\hline Mean & $S D$ & $N$ & $t$-test \\
\hline
\end{tabular}

$\begin{array}{lrrrc}\text { TANF } & 17.312 & 7.431 & 5,185 & - \\ \text { Transit commuters } & 16.827 & 7.866 & 20,616 & <.005 \\ \text { All workers } & 19.355 & 10.795 & 236,634 & <.005\end{array}$

be beneficial if the route network increases overall accessibility to employment opportunities. In this case, the measures of relative access to entry-level job locations are an indicator of route system effectiveness. The comparison of mean employment access through the transit network indicates that there is no significant difference between TANF recipients and frequent transit commuters (Table 3). In addition, the results indicate that there is no statistical difference in employment access between TANF recipients and the overall employed population. In general, TANF recipients do not appear to be at a particular disadvantage in terms of reaching employment locations using transit compared to other transit commuters.

Figure 1 shows the geographic distribution of TANF recipients in the City of Portland. Concentrations of recipients are apparent in the north and northeast portions of the City. The map also shows the correlation between recipi-

\begin{tabular}{|c|c|c|c|c|}
\hline \multicolumn{5}{|c|}{$\begin{array}{l}\text { Table } 3 \\
\text { Relative Accessibility to Entry-Level Jobs }{ }^{a}\end{array}$} \\
\hline & Mean & $S D$ & $N$ & $t$-test \\
\hline TANF & $2,318.3$ & $17,457.4$ & 5,104 & - \\
\hline Transit commuters & $2,412.1$ & $17,173.0$ & 20,422 & .728 \\
\hline All workers & $1,956.1$ & $16,689.7$ & 232,497 & .126 \\
\hline
\end{tabular}

a. Calculated as the combined accessibility to service and retail employment locations. 
ent locations and census block groups ranked by the transit and employment accessibility variables discussed previously. The block group rank for walking distance to the nearest bus stop (a high rank represents closer locations), service frequency at the nearest stop (a high rank represents higher frequency), and employment accessibility (a high rank represents higher accessibility) are added together for a composite rank. The highest values (dark shade) shown on the map represent the areas with the worst relative transit and employment access ( 2 standard deviations above the mean). The correlation between a block group's rank and the presence of TANF recipients (percent of the blockgroup population that are recipients) is not significantly correlated $(R=.0069$, $p=.441$ ). In fact, the area with the highest concentration of TANF recipients also has high levels of transit and employment accessibility. Such findings are relatively common, either from the standpoint of service delivery bias or through spatial constraint (McLafferty 1982).

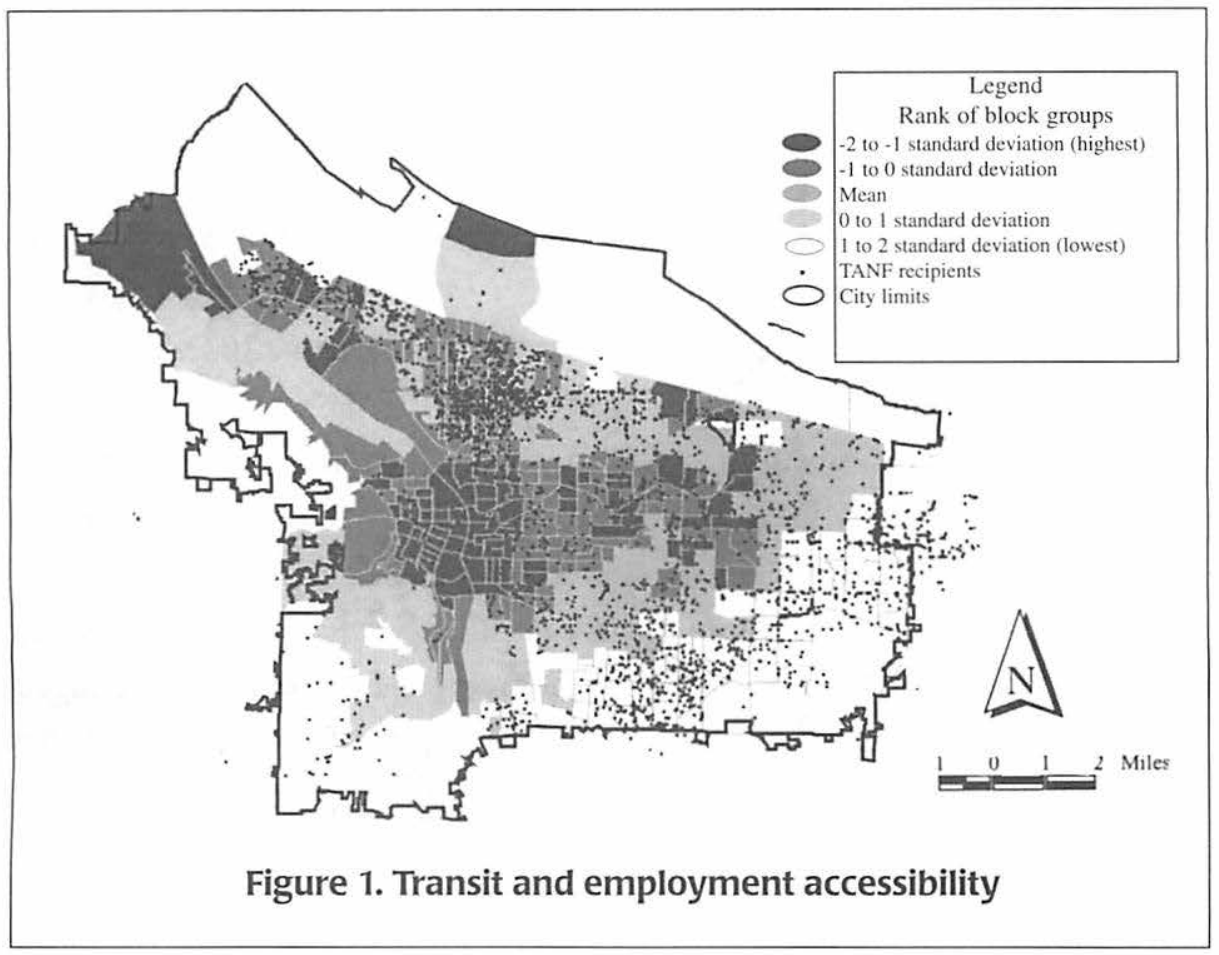




\section{Conclusions}

The three hypotheses examined in this article focus on the relative availability of transit services throughout the City of Portland. Because 85 percent to 90 percent of TANF recipients do not have access to an automobile for personal use, their mobility needs have to be met by alternative means (U.S. DOT 1998). The results of this analysis indicate that TANF recipients realize levels of transit and employment accessibility similar to those of employed transit commuters. An explanation for this is that mobility needs are complex and may not be satisfied by conventional increases in public transit service such as additional routes or increased service frequency.

In order to meet the mobility needs of low-income and unemployed persons, a variety of strategies are being implemented. For example, the Joblinks demonstration program in 10 U.S. cities used a variety of transportation services including demand-responsive van service, fixed-route reverse commute express bus service, school buses, volunteer carpools, demand-responsive taxi, and extended-hour demand-responsive transit (Goldenberg, Zhang, and Dickson 1998). Effective mobility strategies will need to provide high levels of service beyond the traditional A.M. and P.M. peak hours, for late-night to early-morning shifts. With conventional transit service, workers relying on transit may be able to reach their work locations by transit but service may not be available when their shifts are over. This is where demand-responsive and extended-hour services can be especially valuable in meeting specific employment-related mobility needs.

Public transit can better respond to welfare-to-work challenges if it can provide "collaboration among transportation, employment, and other human services organizations" (U.S. General Accounting Office 1998). Public transit planners are recognizing that employers must be involved in the design and implementation of work-related transportation strategies. Human service agencies also understand the transportation mobility needs of TANF recipients that extend beyond employment-related travel. To effectively address these transportation mobility needs, other destinations that are part of daily travel needs (e.g., shopping, school, childcare, healthcare, and job-training locations) must 
also be considered. Because a vast majority of TANF recipients do not own cars, simply providing transportation to work and back only meets a portion of their daily travel requirements.

Further research is needed that combines measures of employment accessibility with other measures of access to shopping, schools, and daycare center locations to better assess overall transportation mobility needs. In addition, similar analyses need to be performed in a variety of urban locations so that generalizable results can be obtained. Mobility strategies may need to place more emphasis on these nonwork locations to meet the daily travel needs of the low-income population and persons seeking employment. Alternatively, further research may indicate that publicly provided transit services do not significantly affect TANF recipient employment opportunities. In this case, resources should be coordinated to address other contributing factors including education, job training, childcare, health services, and affordable housing.

\section{References}

Black, A. 1995. Urban mass transportation planning. New York: McGraw-Hill, Inc. Community Transportation Association of America. 1998. Access to jobs: A guide to innovative practices in welfare-to-work transportation. Washington, DC: CTAA.

Coulton, C., L. Leete, and N. Bania. 1997. "Housing, transportation and access to suburban jobs by welfare recipients in the Cleveland area." Center for Urban Poverty and Social Change, Mandel School of Applied Social Sciences, Case Western Reserve University.

Danziger, S., M. Corcoran, S. Danziger, C. Heflin, A. Kalil, J. Levine, D. Rosen, K. Seefeldt, K. Siefert, and R. Tolman. 1999. Barriers to the employment of welfare recipients. Poverty Research and Training Center, University of Michigan.

Goldenberg, L., J. Zhang, and C. Dickson. 1998. “Assessment of the Joblinks demonstration projects: Connecting people to the workplace and implications for welfare reform." Paper presented at the 1998 annual Transportation Research Board Meeting, Washington, DC.

Ihlanfeldt, K. R., and D. L. Sjoquist. 1998. The spatial mismatch hypothesis: A review of recent studies and their implications for welfare reform. Housing Policy Debate 9(4): 849-892. 
Immergluck, D. 1998. Job proximity and the urban employment problem: Do suitable nearby jobs improve neighborhood employment rates? Urban Studies 35: 7-23.

Lacombe, A., and W. Lyons. Spring 1998. The transportation system's role in moving welfare recipients to jobs. Volpe Transportation Journal (2): 1-9.

McLafferty, S. 1982. Urban structure and geographical access to public services. Annals of the Association of American Geographers 72(3): 347-354.

Murakami, E., and J. Young. 1997. "Daily travel by persons with low income." Paper presented at the National Personal Transportation Survey Symposium, Bethesda, Maryland.

Ong, P., and E. Blumenberg. 1998. Job access, commute and travel burden among welfare recipients. Urban Studies 35(1): 77-93.

Sanchez, T. W. 1999. The connection between public transit and employment: The cases of Portland and Atlanta. Journal of the American Planning Association 65(3): 284-296.

Shen, Q. 1998. Location characteristics of inner-city neighborhoods and employment accessibility of low-wage workers. Environment and Planning B 25: 345-365.

Surface Transportation Policy Project. 1998. Getting to work: The access to jobs and reverse commute programs. Progress VIII(4): 10.

Thompson, G. L. 1997. How ethnic/racial groups value transit accessibility: Modeling inferences from Dade County. Paper presented at the annual meeting of the American Collegiate Schools of Planning, Ft. Lauderdale, Florida.

Urban Mass Transportation Administration. 1979. Analyzing transit options for small urban communities-Analysis methods. Washington, DC: U.S. Department of Transportation.

U.S. Department of Transportation. 1998. Bureau of Transportation Statistics. Welfare reform and access to jobs in Boston. Report BTS -98-A-02. Washington, DC.

U.S. General Accounting Office. 1998. "Welfare reform: Transportation's role in moving from welfare to work." GAO/RCED-98-161, Washington, DC.

Wachs, M. 1995. "The political context of transportation policy," in S. Hanson, (ed.), The geography of urban transportation. New York: The Guilford Press, 269-286. Wachs, M., and B. D. Taylor. 1998. Can transportation strategies help meet the welfare challenge? Journal of the American Planning Association 64(1): 15-19. 


\section{About the Author}

Thomas W. SANChez (sanchez@pdx.edu) is an assistant professor of urban studies and planning and a research associate in the Center for Urban Studies at Portland State University. His research focuses on the social and spatial impacts of transportation planning. 